\title{
Interleukin-10 gene modification attenuates hepatocyte activation of rat hepatic stellate cells in vitro
}

\author{
YUN-XIN CHEN, YUE-HONG HUANG, WEI-DA ZHENG, ZHI-XIN CHEN, \\ LI-JUAN ZHANG and XIAO-ZHONG WANG
}

Department of Gastroenterology, Union Hospital of Fujian Medical University, Fuzhou 350001, Fujian, P.R. China

Received July 7, 2012; Accepted November 6, 2012

DOI: $10.3892 / \mathrm{mmr} .2012 .1228$

\begin{abstract}
Activation of hepatic stellate cells (HSCs) plays a key role in the progression of liver fibrosis. Interleukin-10 (IL-10), a potential anti-fibrosis cytokine, has an unfavorable pharmacokinetic profile, which limits its clinical applications. A liver-targeting gene delivery system may maintain a longerlasting concentration in hepatic tissue with fewer side-effects in non-target tissues. In the present study, when delivered by asialoglycoprotein receptor-mediated liposomes, the IL-10 gene was highly expressed in BRL cells (a rat hepatocyte line) and attenuated the apoptosis of BRL cells induced by plasmid transfection. In a co-culture system, BRL cells demonstrated a marked ability to stimulate the proliferation of primary HSCs and their expression of $\alpha$-SMA and procollagen type I. Following modification of the BRL cells with the IL-10 gene, this stimulation was attenuated and an accelerated apoptosis of the HSCs was induced. These results suggest that hepatocyte-targeting gene delivery may be an ideal technique for the IL-10 gene therapy of liver fibrosis, which requires further confirmation by in vivo studies.
\end{abstract}

\section{Introduction}

Liver fibrosis is the common sequel of diverse chronic liver disease, characterized by increased deposition and altered composition of the extracellular matrix (ECM). Its pathogenesis is a multi-cellular event, involving Kupffer cells, hepatocytes, intrahepatic lymphocytes and hepatic stellate cells (HSCs), among others. It is generally accepted that HSCs are central to the process of fibrosis as they are the major source of ECM and their activation to form myofibroblasts is the key event in fibrosis, characterized by increasing proliferation, chemotaxis, contractility and fibrogenesis (1).

Correspondence to: Dr Xiao-Zhong Wang, Department of Gastroenterology, Union Hospital of Fujian Medical University, 29 Xinquan Road Gulou, Fuzhou 350001, Fujian, P.R. China

E-mail: xiaozhongwang@yeah.net

Key words: interleukin-10, liver fibrosis, hepatic stellate cell, hepatocyte, gene therapy, cytokine
A number of studies in animal models and data in human liver disease emphasize that fibrosis is reversible (2). To date, no effective pharmacologic treatment able to prevent the progression of liver fibrosis is available. Interleukin-10 (IL-10) is a cytokine that downregulates pro-inflammatory responses and has a potential modulatory effect on liver fibrosis $(3,4)$. Recombinant human IL-10 has been produced and tested in clinical trials. It was shown in a study by Nelson et al that the administration of IL-10 to patients with hepatitis $\mathrm{C}$ virus (HCV) infection attenuated liver inflammation and subsequent fibrosis (5). Furthermore, the inhibitory effect of IL-10 on hepatic fibrogenesis was confirmed by our previous study in experimental rat models of liver cirrhosis induced by carbon tetrachloride (6).

However, the elimination half-life of recombinant IL-10 in vivo is relatively short, and its non-targeted administration may lead to systemic side-effects (7). Therefore, increasing numbers of studies have aimed to use IL-10 gene transfer to maintain the level of IL-10, especially in the target organs, with as low a frequency of administration as possible. A previous study revealed that electro-transfer of the IL-10 gene into the anterior tibialis muscle was followed by attenuation of $\mathrm{CCl}_{4}$-induced liver fibrosis in mice (8). However, liver-targeting gene transfer is undoubtedly more acceptable in the management of liver diseases, due to its conceivably fewer systemic side-effects. We hypothesize that hepatocytes are the ideal target cells of IL-10 gene transfer due to their quantitative dominance in the liver and their expression of several specific molecules, including the asialoglycoprotein receptor, which should facilitate the targeting gene transfer.

To confirm this hypothesis, BRL cells, an immortalized rat hepatocyte line, were transfected with the IL-10 gene by asialoglycoprotein receptor-mediated liposomes and co-cultured with primary HSCs. We then investigated whether the IL-10 expressed by the BRL cells affected the activation of HSCs in vitro.

\section{Materials and methods}

Vector construction. Construction of the IL-10 eukaryotic expression vector was performed as described previously (9). Briefly, the total RNA of peripheral blood mononuclear cells from Sprague-Dawley rats was isolated using a Purescript RNA Isolation kit (Gentra Systems, Inc., Minneapolis, MN, 
USA) and cDNA was obtained by reverse transcription (RT; Promega, Madison, WI, USA). The full-length coding region of IL-10 containing restriction sites was amplified by nested polymerase chain reaction (PCR; Promega). In the first PCR step, $2 \mu \mathrm{l}$ cDNA product was used as the template to amplify specific fragments without primer. Then, $2 \mu$ l product of the first PCR was used as the template to amplify the full-length coding region of IL-10 with nested primers, including the restriction sites of HindIII and BamHI. PCR was performed with an initial denaturation at $94^{\circ} \mathrm{C}$ for $5 \mathrm{~min}$, followed by 30 cycles at $94^{\circ} \mathrm{C}$ for $45 \mathrm{sec}$, annealing at $61^{\circ} \mathrm{C}$ (nested primer at $58^{\circ} \mathrm{C}$ ) for $45 \mathrm{sec}$ and at $72^{\circ} \mathrm{C}$ for $60 \mathrm{sec}$, with a final extension at $72^{\circ} \mathrm{C}$ for $7 \mathrm{~min}$. The sequences of the primers were as follows: outer primer: sense, 5'-cgcagcttgcagaaaacagagc-3'; antisense, 5'-gctctatttatgtcctgcagtccag-3'; nested primer: sense, 5'-cgaagcttgccaccatgcttggctcagcac-3'; and antisense, 5'-cgtcta gatcaattttcatttgagtg-3'. The PCR product was digested with HindIII and BamHI (Promega), then cloned into the eukaryotic expression vector pcDNA3.0 (Invitrogen, Carlsbad, CA, USA) to establish the recombinant plasmid pcDNA3.0-IL-10, which was verified by restriction endonuclease digestion and direct DNA sequencing.

Cell transfection and RT-PCR. BRL cells, an immortalized normal rat hepatocyte line obtained from cell bank of Academia Sinica, Shanghai, China, were routinely seeded into 50-ml plastic flasks and cultivated in DMEM supplemented with $10 \%$ fetal bovine serum (FBS) and $1 \%$ antibiotics (penicillin/streptomycin) in a humidified incubator containing 5\% $\mathrm{CO}_{2}$ at $37^{\circ} \mathrm{C}$. Cells in the logarithmic growth phase were transfected with plasmid pcDNA3.0-IL-10 using TransFast ${ }^{\mathrm{TM}}$ liposomes (Promega) and JetPEI ${ }^{\mathrm{TM}}-$ Gal liposomes (Polyplus Transfection, New York, NY, USA), separately. The transfection system contained $3 \mathrm{mg}$ DNA and $9.6 \mathrm{ml}$ liposome JetPEI-Gal or $9 \mathrm{ml}$ liposome TransFast per flask. Transfection was performed according to the manufacturer's instructions and continued for $24 \mathrm{~h}$. The cells were then trypsinized and

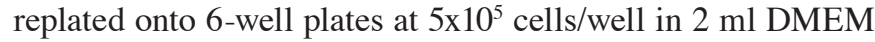
containing $10 \%$ FBS. The total RNA was isolated from the cells of each group at $0,1,2,4,8,12$ and 16 days post-transfection and then reverse transcribed to cDNA as a template. IL-10 and $\beta$-actin were amplified together by PCR. The primer for IL-10 was the nested primer described above. The sequences of the $\beta$-actin primers were sense, $5^{\prime}$-ccaaccgtgaaaagatgacc-3' and antisense, 5'-caggaggagcaatgatcttg-3'. The PCR was carried out as follows: pre-denaturation at $95^{\circ} \mathrm{C}$ for $5 \mathrm{~min}$, 22 amplification cycles (denaturation at $94^{\circ} \mathrm{C}$ for $45 \mathrm{sec}$, annealing at $57^{\circ} \mathrm{C}$ for $45 \mathrm{sec}$ and extension at $72^{\circ} \mathrm{C}$ for $1 \mathrm{~min}$ ) and a final extension at $72^{\circ} \mathrm{C}$ for $7 \mathrm{~min}$. The product of PCR was detected on $1.8 \%$ agarose gel.

ELISA. The BRL cells were seeded into plastic cell culture flasks and cultured in DMEM containing 10\% FBS. The cells in the logarithmic growth phase were separately transfected with plasmids pcDNA3.0-IL-10 and pcDNA3.0 using JetPEI-Gal liposomes and the transfection was continued for $24 \mathrm{~h}$. The supernatants of the two groups (BRL/pcDNA3.0-IL-10, BRL/pcDNA3.0) were harvested and refreshed every day until 16 days post-transfection. The IL-10 in the supernatant 1, 2, $4,8,12,16,20$ and 24 days post-transfection was detected by
ELISA (Biosource, Camarillo, CA, USA) according to the manufacturer's instructions.

MTT assay. BRL cells were seeded in 96-well microplates at $5 \times 10^{3}$ cells/well in $200 \mu \mathrm{l}$ DMEM containing $10 \%$ FBS. After $24 \mathrm{~h}$ incubation, the supernatant was refreshed. The BRL cells were divided into three groups (groups C, P and I) randomly and group $\mathrm{P}$ were transfected with plasmid pcDNA3.0 and group I with plasmid pcDNA3.0-IL-10 using JetPEI-Gal liposomes. At 24 and 48 h post-transfection, $20 \mu \mathrm{l}$ 3-(4,5-dimethyl2-thiazolyl)-2,5-diphenyl-2H-tetrazolium bromide (MTT; $5 \mathrm{mg} / \mathrm{ml}$ ) was added to each well, and the plates were incubated for an additional $4 \mathrm{~h}$. The supernatant was then discarded, $150 \mu \mathrm{l}$ dimethyl sulfoxide (DMSO) was added to each well and the optical density at $490 \mathrm{~nm}$ was measured with a microplate reader.

Flow cytometric analysis. BRL cells were planted into 6-well plastic plates, then grouped and transfected as described above. At $48 \mathrm{~h}$ post-transfection, the cells were harvested and incubated with Annexin V-FITC and PI (Bender MedSystems, Vienna, Austria) and the cell apoptosis rate was analyzed by flow cytometry.

Hepatic stellate cell isolation and culture. HSCs were isolated from male Sprague-Dawley rats weighing 450-500 $\mathrm{g}$ by means of sequential perfusion with collagenase and pronase $\mathrm{E}$, and subsequent Nycodenz gradient centrifugation as previously described elsewhere (10). Desmin immunocytochemistry demonstrated an isolated HSC purity of $>95 \%$. The HSCs were seeded into 6 -well plastic tissue culture plates at a density of $2 \times 10^{5}$ cells/well in DMEM containing 20\% FBS and incubated in a humidified incubator containing $5 \% \mathrm{CO}_{2}$ at $37^{\circ} \mathrm{C}$. The culture medium was replaced with DMEM containing 10\% FBS $24 \mathrm{~h}$ after plating.

Co-culture of BRL cells and primary HSCs. BRL cells seeded at equal density in plastic cell culture flasks were divided into three groups and separately transfected with plasmid pcDNA3.0-IL-10, pcDNA3.0 and normal saline as described previously. Post-transfection, the cells were digested and seeded onto 30-mm filter inserts (Millipore, Billerica, MA, USA) placed in 6 -well culture plates at $2 \times 10^{5}$ cells/ insert in $3 \mathrm{ml}$ DMEM containing $10 \%$ FBS. After $24 \mathrm{~h}$, the inserts planted with BRL were placed into the 6-well plastic tissue culture plates which had been planted with primary HSCs for 3 days and the culture medium was refreshed. The co-culture cells were divided into 4 groups: group $\mathrm{H}$, HSCs; group C, HSCs/BRL transfected with normal saline; group P, HSCs/BRL transfected with pcDNA3.0; and group I, HSCs/BRL transfected with pcDNA3.0-IL-10. The co-culturing was terminated after $48 \mathrm{~h}$.

Western blotting. After the indicated number of days, the inserts with BRL cells and supernatant were discarded. The HSCs were washed with PBS twice and lysed with cell lytic buffer containing $50 \mathrm{mM}$ Tris $\mathrm{pH} 8.0,150 \mathrm{mM} \mathrm{NaCl}$, $0.2 \mathrm{mg} / \mathrm{ml} \mathrm{NaN}_{3}, 1 \mathrm{mg} / \mathrm{ml} \mathrm{SDS}, 0.1 \mathrm{mg} / \mathrm{ml}$ aprotinin, $10 \mathrm{mg} / \mathrm{ml}$ $\mathrm{NP}-40,5 \mathrm{mg} / \mathrm{ml}$ sodium deoxycholate and $0.1 \mathrm{mg} / \mathrm{ml}$ phenylmethylsulfonyl fluoride, and the supernatants were obtained after centrifuging at $1,500 \mathrm{x} \mathrm{g}$ for $10 \mathrm{~min}$. The protein concen- 


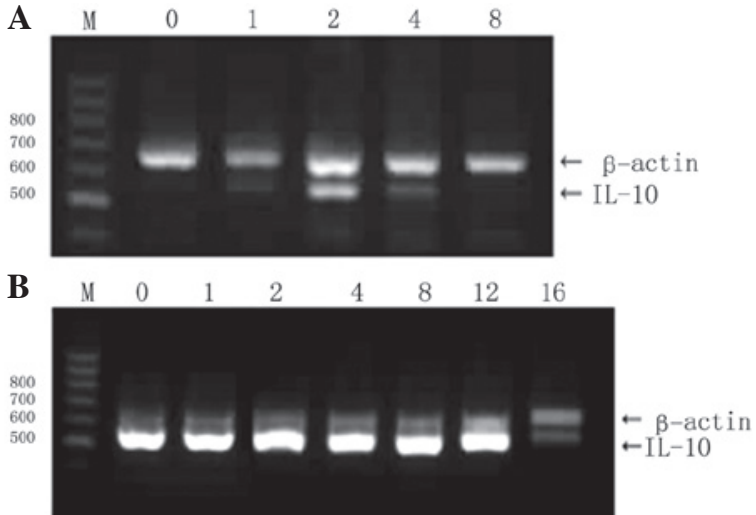

Figure 1. Expression of interleukin-10 (IL-10) mRNA in BRL cells transfected using different liposomes. (A) Transfection using TransFast liposomes (B) transfection using JetPEI-Gal liposomes. M, 100 bp DNA markers; $0,1,2,4,8,12$ and 16 days post-transfection.

trations of the cytosolic extracts were determined by Bradford protein assay. Equal amounts of protein were separated on a $12 \%$ SDS-polyacrylamide gel and transferred onto nitrocellulose membranes. Monoclonal antibodies of procollagen type I, $\alpha$-SMA and $\beta$-tubulin (Santa Cruz Biotechnology, Inc., Santa Cruz, CA, USA) were used at dilution of 1:200, followed by incubation with homologous secondary antibody labeled with HRP. The signals were visualized using an ECL kit.

Terminal dUTP nick-end labeling (TUNEL) assay for apoptosis of HSCs. After the indicated number of days, the inserts with BRL cells and supernatant were discarded. The HSCs were washed with PBS twice and fixed for $1 \mathrm{~h}$ at $37^{\circ} \mathrm{C}$. A TUNEL assay was performed following the manufacturer's instructions (Beijing Zhongshan Co., Beijing, China). The cells were then analyzed under a microscope. The apoptotic cells which had brown nuclei were counted among 3,000 cells/well.

MTT assay of HSCs. BRL cells seeded at equal density in plastic cell culture flasks were divided into three groups (groups I, P and C) and separately transfected with plasmid pcDNA3.0-IL-10, pcDNA3.0 and normal saline as described earlier. Post-transfection, the cells were digested and seeded onto 6-well plastic cell culture plates at $2 \times 10^{5}$ cells/well in $3 \mathrm{ml}$ DMEM containing 10\% FBS. To the other three wells were added $3 \mathrm{ml}$ DMEM containing 10\% FBS without BRL cells as group $\mathrm{H}$. After $48 \mathrm{~h}$, the supernatant of each group was harvested.

The primary HSCs were isolated and planted into 96-well plastic cell culture plates at a density of $5 \times 10^{3}$ per well and incubated for $72 \mathrm{~h}$. The supernatant was refreshed with $100 \mu \mathrm{l}$ DMEM containing 10\% FBS. The HSCs were divided into four groups (groups H, C, P and I) randomly, and the harvested supernatants were added (100 $\mu \mathrm{l}$ per well). After $48 \mathrm{~h}$, the MTT assay was performed as previously described.

Statistical analysis. The data from the TUNEL assay were assessed using the $\chi^{2}$ test. All other data are expressed as the mean $\pm \mathrm{SE}$ and were from at least three independent experiments assessed by the method of analysis of variance (ANOVA). Data from three or more groups were assessed using

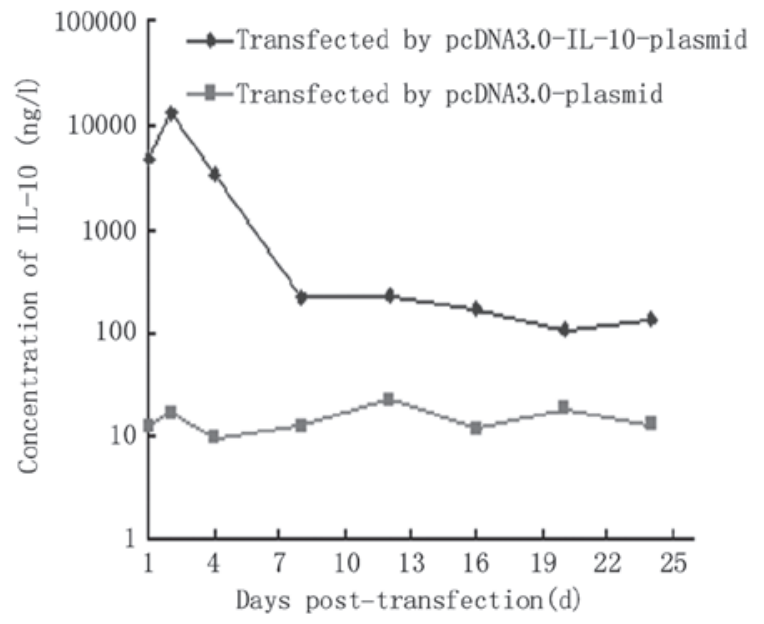

Figure 2. Expression of interleukin-10 (IL-10) protein.

the Kruskall-Wallis test. When significant, post hoc multiple comparisons were archived using the Student-Newman-Keuls method. The analyses were performed using SigmaStat software (SPSS, Chicago, IL, USA). P<0.05 was considered to indicate a statistically significant result.

\section{Results}

Construction of IL-10 expression vector. The IL-10 gene (559 bp) was prepared by nested PCR and successfully cloned into plasmid pcDNA3.0. It was confirmed by restriction endonuclease digestion and DNA sequencing.

Transfection efficiency. To select a vector for more efficient gene delivery to hepatocytes, a frequently used liposome, TransFast, and an asialoglycoprotein receptor-mediated liposome, JetPEI-Gal, were employed. As shown in Fig. 1A, the TransFast liposomes displayed a lower transfection efficiency, characterized by a low peak of IL-10 mRNA expression in the BRL cells, followed by a rapid drop and disappearance at 8 days post-transfection. The transfection efficiency of JetPEI-Gal liposomes for hepatocytes was significantly higher. The expression levels of IL-10 mRNA in the BRL cells transfected using the JetPEI-Gal liposomes were much higher than those of $\beta$-actin. The levels peaked quickly following transfection, were stable until 12 days post-transfection and then dropped at 16 days post-transfection (Fig. 1B).

Expression of IL-10 protein by BRL cells. It would clearly be valuable if high and enduring expression levels of IL-10 protein were able to be induced. While almost no IL-10 was secreted by the BRL cells transfected with the pcDNA3.0 plasmid, there was a high level of secretory IL-10 in the supernatant of the BRL cells transfected with the pcDNA3.0-IL-10 plasmid which reached a peak of $12.78 \mu \mathrm{g} / 1$ at 2 days post-transfection, then dropped rapidly and remained at a low level from 8 days post-transfection for at least 16 days (Fig. 2). A divergence phenomenon between the mRNA and protein expression levels of IL-10 in the late phase was observed, implying the presence of translational suppression. The results presented so far have been reported previously (9). 
Table I. Relative gray scale of $\alpha$-SMA and procollagen type I for HSCs (mean $\pm \mathrm{SD}, \mathrm{n}=4$ ).

\begin{tabular}{lcc}
\hline Group & $\alpha-S M A /$ tubulin & Procollagen type I/tubulin \\
\hline Group H & $0.812 \pm 0.095$ & $0.298 \pm 0.047$ \\
Group C & $1.376 \pm 0.108^{\mathrm{a}}$ & $1.428 \pm 0.110^{\mathrm{a}}$ \\
Group P & $1.416 \pm 0.097^{\mathrm{a}}$ & $1.538 \pm 0.083^{\mathrm{a}}$ \\
Group I & $0.741 \pm 0.068^{\mathrm{b}}$ & $0.515 \pm 0.114^{\mathrm{b}}$ \\
\hline
\end{tabular}

HSCs, hepatic stellate cells; group H, HSCs; groups C, P and I, HSCs co-cultured with BRL cells transfected with normal saline, pcDNA3.0 and pcDNA3.0-IL-10, respectively. ${ }^{a} \mathrm{P}<0.01$ vs. group $\mathrm{H}$; ${ }^{\mathrm{b}} \mathrm{P}<0.01$ vs. group $\mathrm{P}$.

Proliferation and apoptosis of BRL cells. Having demonstrated the high transfection efficiency of JetPEI-Gal liposomes to hepatocytes, it was important to ascertain the effects of plasmid transfection and IL-10 gene expression on the proliferation and apoptosis of BRL cells. No significant deviations among the viable counts of the control and transfected cells were observed during the first $24 \mathrm{~h}$ posttransfection $(\mathrm{P}>0.05)$. At $48 \mathrm{~h}$ post-transfection, the viable count of the BRL cells transfected with the pcDNA3.0 plasmid was visibly but slightly decreased compared with that of the control BRL cells $(\mathrm{P}<0.01)$, but there was no significant deviation between the BRL cells transfected with the pcDNA3.0 plasmid and those transfected with the pcDNA3.0-IL-10 plasmid ( $>0.05$; Fig. 3 ). The apoptosis of each group was detected by flow cytometry. As shown in Fig. 4, the BRL cells transfected with the pcDNA3.0 plasmid had a significantly higher apoptosis rate $(11.13 \pm 0.97 \%)$ than the control BRL cells $(5.91 \pm 0.37 \%$; $\mathrm{P}<0.01)$. This increased apoptosis was markedly attenuated in the BRL cells transfected with pcDNA3.0-IL-10 plasmid, which had an apoptosis rate of $7.36 \pm 0.51 \%(\mathrm{P}<0.01)$.

Phenotype diversity of HSCs. Following isolation and primary culturing for 5 days, the HSCs of group $\mathrm{H}$ fully stretched to a stellate shape. The HSCs cocultured with BRL cells (groups C, $\mathrm{P}$ and I) clearly contracted into fusiform or dendritic shapes, as shown in Fig. 5.

Expression of $\alpha$-SMA and procollagen type I in HSCs. HSC activation is accompanied by increased expression of $\alpha$-SMA and the production of collagen types I and III. Setting $\beta$-tubulin as an internal reference, the expression levels of procollagen type I and $\alpha$-SMA by HSCs were detected by western blot analysis. As shown in Fig. 6, BRL cells significantly stimulated the expression of procollagen type I and $\alpha$-SMA by HSCs. In the BRL cells transfected with the IL-10 gene, this stimulation was suppressed (Table I).

Proliferation of HSCs. Increased proliferation is an important feature of HSC activation. In MTT assays, HSCs displayed a marked increase in proliferation when cultured in the supernatant of BRL cells $(\mathrm{P}<0.01)$. By contrast, when cultured in the supernatant of BRL cells transfected with the IL-10 gene, the

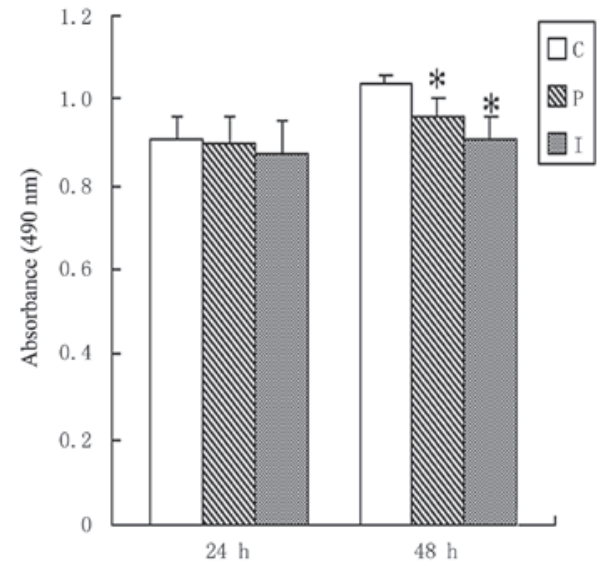

Figure 3. Proliferation of BRL cells in various groups. C, control BRL cells; P, BRL cells transfected with pcDNA3.0 plasmid; I, BRL cells transfected with pcDNA3.0-IL-10 plasmid. " $\mathrm{P}<0.01$ vs. group C.
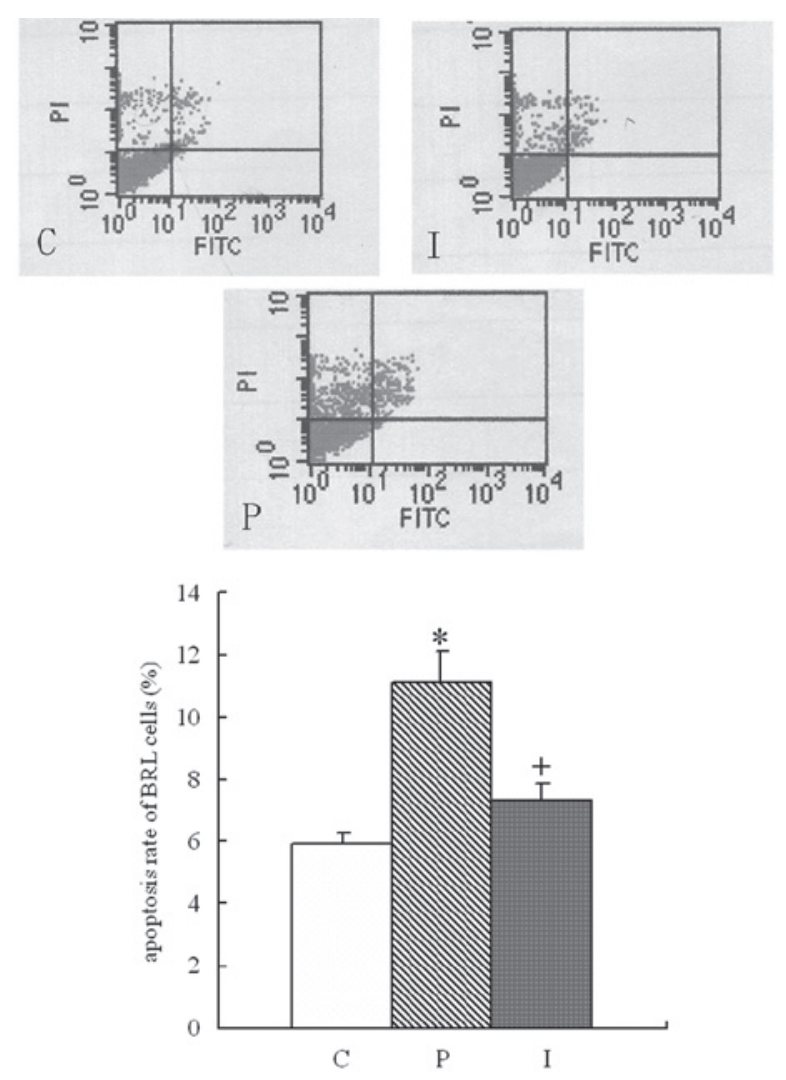

Figure 4. Apoptosis of BRL cells in each group. C, control BRL cells; $\mathrm{P}$, BRL cells transfected with pcDNA3.0 plasmid; I, BRL cells transfected with pcDNA3.0-IL-10 plasmid. ${ }^{*} \mathrm{P}<0.01$ vs.group $\mathrm{C},{ }^{+} \mathrm{P}<0.01$ vs.group $\mathrm{P}$.

increased proliferation of the HSCs was significantly attenuated $(\mathrm{P}<0.01)$, as shown in Fig. 7 and Table II.

Apoptosis of HSCs. The apoptosis of activated HSCs may be involved in the reversion of liver fibrosis. We aimed to establish whether BRL cells with or without IL-10 gene modification affected the apoptosis of HSCs. Following isolation and primary culturing for several days, the HSCs displayed such strong adhesion that it was difficult to digest them from the 
Table II. Absorbance values of HSCs (mean \pm SD, $n=8)$.

\begin{tabular}{lr}
\hline Group & Absorbance \\
\hline Group H & $0.143 \pm 0.013$ \\
Group C & $0.261 \pm 0.021^{\text {a }}$ \\
Group P & $0.282 \pm 0.020^{\mathrm{a}}$ \\
Group I & $0.135 \pm 0.014^{\mathrm{b}}$ \\
\hline HSCs, hepatic stellate cells; group H, HSCs; groups C, P and I, & \\
HSCs co-cultured with BRL cells transfected with normal saline, \\
pcDNA3.0 and pcDNA3.0-IL-10, respectively. ${ }^{\text {a }}<0.01$ vs. group H; \\
${ }^{\mathrm{b}} \mathrm{P}<0.01$ vs. group P. \\
\hline
\end{tabular}

culture plates and separate them from each other. Therefore, TUNEL assays but not flow cytometry, were employed to detect the apoptosis rate of the HSCs. As shown in Fig. 8, there were few apoptotic HSCs in group $\mathrm{H}$; the apoptosis rate was $5.9 \%$. However, the apoptosis rate was clearly increased in the HSCs cocultured with BRL cells (14.65\% in group C and $14.45 \%$ in group $\mathrm{P}$ ), which is in parallel with the increased proliferation described earlier. It is a notable finding that further increased apoptosis $(20.35 \%)$ was detected in the HSCs co-cultured with the BRL cells transfected with the IL-10 gene $(\mathrm{P}<0.01$; Table III).

\section{Discussion}

Considerable evidence suggests that IL-10 is a promising antifibrotic agent. Nevertheless, the unfavorable pharmacokinetic profile of IL-10 may limit the clinical application of this cytokine. In healthy human volunteers, intravenous administration of recombinant human IL-10 resulted in a rapid disappearance from the circulation (11). Another study in rats with liver fibrosis induced by bile duct ligation revealed that renal clearance contributed to an even shorter half-life of IL-10 and an increased hepatic uptake (2-fold), possibly mediated by markedly elevated IL-10 receptor expression in the fibrotic livers (12). Moreover, the distribution in non-target tissues and its multiple effects in normal physiological processes also strongly hamper the clinical application of IL-10.

It is conceivable that liver-targeting IL-10 gene amplification may maintain a more enduring drug concentration in hepatic tissue with minimal side-effects in non-target tissues. The selection of suitable target cells and gene delivery system is essential. HSCs appear to be the optimal target cells due to their key role in liver fibrosis. The successful modification of IL-10 with mannose 6-phosphate (M6P), which targets the mannose 6-phosphate/insulin-like growth factor II (M6P/ IGFII) receptor expressed on activated HSCs, has been reported (7). However, in addition to inhibiting the activation of HSCs by direct interaction with the IL-10 receptor (13), IL-10 has anti-fibrotic activity, mediated mainly by the inhibition of the production of superoxide and TNF by Kupffer cells, reduction of the production of proinflammatory cytokines (TNF- $\alpha$, IL-12, and IFN- $\gamma$ ), reduction of neutrophil infiltration and attenuation of the increase of $\mathrm{CD} 8^{+} \mathrm{T}$ cells in the liver $(3,14,15)$. Therefore, a liver-targeting IL-10 gene delivery
Table III. Apoptosis rates of HSCs.

\begin{tabular}{lcc}
\hline Group & Positive cell population & Apoptosis rate $(\%)$ \\
\hline Group H & 118 & 5.9 \\
Group C & 293 & $14.65^{\mathrm{a}}$ \\
Group P & 289 & $14.45^{\mathrm{a}}$ \\
Group I & 407 & $20.35^{\mathrm{ab}}$ \\
\hline
\end{tabular}

HSCs, hepatic stellate cells; Group H, HSCs; groups C, P and I, HSCs co-cultured with BRL cells transfected with normal saline, pcDNA3.0 and pcDNA3.0-IL-10, respectively. ${ }^{a} \mathrm{P}<0.01$ vs. group $\mathrm{H}$; ${ }^{\mathrm{b}} \mathrm{P}<0.01$ vs. group $\mathrm{P}$.

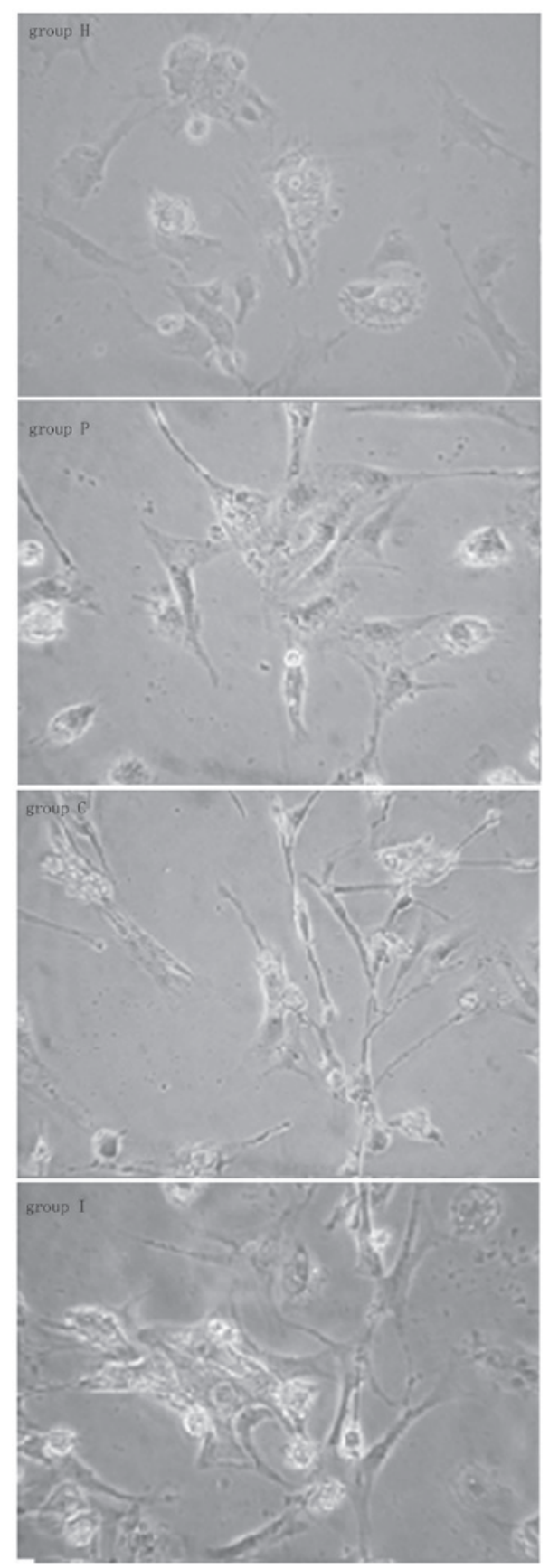

Figure 5. Hepatic stellate cell (HSC) phenotypes. Group H, HSCs; groups C, $\mathrm{P}$ and I, HSCs co-cultured with BRL cells transfected with normal saline, pcDNA3.0 and pcDNA3.0-IL-10, respectively. 


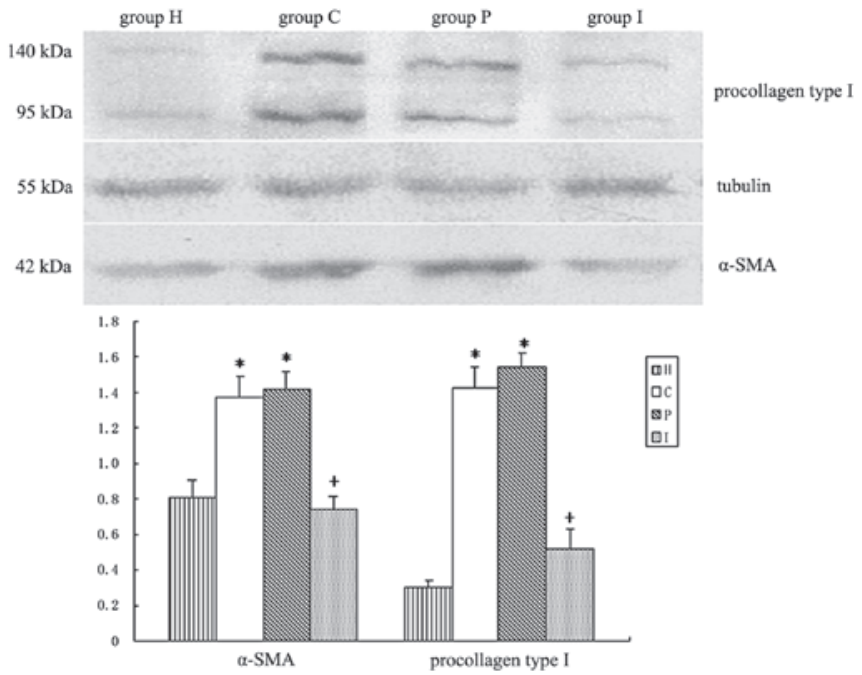

Figure 6. Protein expression of $\alpha$-SMA and procollagen type I in hepatic stellate cells (HSCs). Group H, HSCs; groups C, P and I, HSCs co-cultured with BRL cells transfected with normal saline, pcDNA3.0 and pcDNA3.0-IL-10, respectively. ${ }^{*} \mathrm{P}<0.01$ vs. group $\mathrm{H} ;{ }^{+} \mathrm{P}<0.01$ vs. group $\mathrm{P}$.

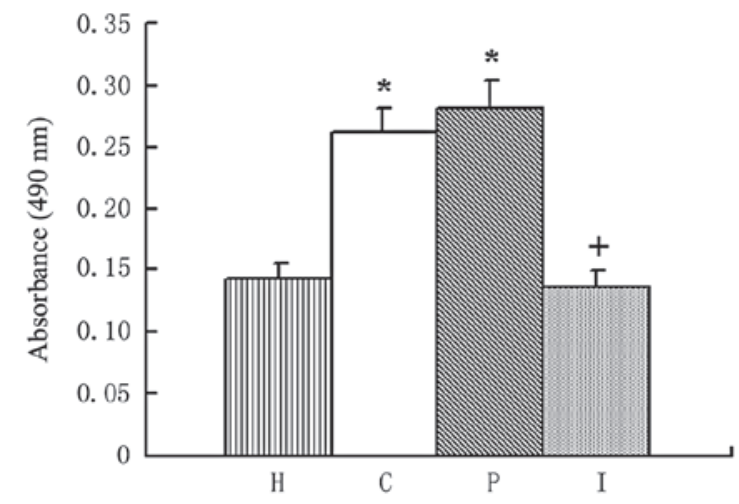

Figure 7. Proliferation of hepatic stellate cells (HSCs). H, HSCs; C, P and I, HSCs co-cultured with BRL cells transfected with normal saline, pcDNA3.0 and pcDNA3.0-IL-10, respectively. ${ }^{*} \mathrm{P}<0.01$ vs. group $\mathrm{H} ;{ }^{+} \mathrm{P}<0.01$ vs. group $\mathrm{P}$.

system may be more efficient than a HSC-targeting one. We hypothesize that hepatocytes would be the ideal target cells of IL-10 gene transfer for the following reasons: i) hepatocytes constitute the majority cells in the liver, so a high expression level of the target gene may be anticipated; ii) hepatocytes are adjacent to all other hepatic cells, including HSCs, and may have a paracrine action; iii) several hepatocyte-specific expression molecules, including the asialoglycoprotein receptor, have been well studied. Delivery systems focused on these molecules are considerably mature and even commercialized, and so may be utilized directly in experimental and clinical treatment $(16,17)$.

In certain IL-10 gene-targeting studies, viral delivery, especially using an adenoviral vector, has displayed a high transfection efficiency followed by significant attenuation of the fibrotic process or acute rejection following organ transplantation $(18,19)$. However, apart from the biological safety issues, adenoviral vectors may provoke an intensive immune response leading to a marked reduction of transfection efficiency upon further administration, which is
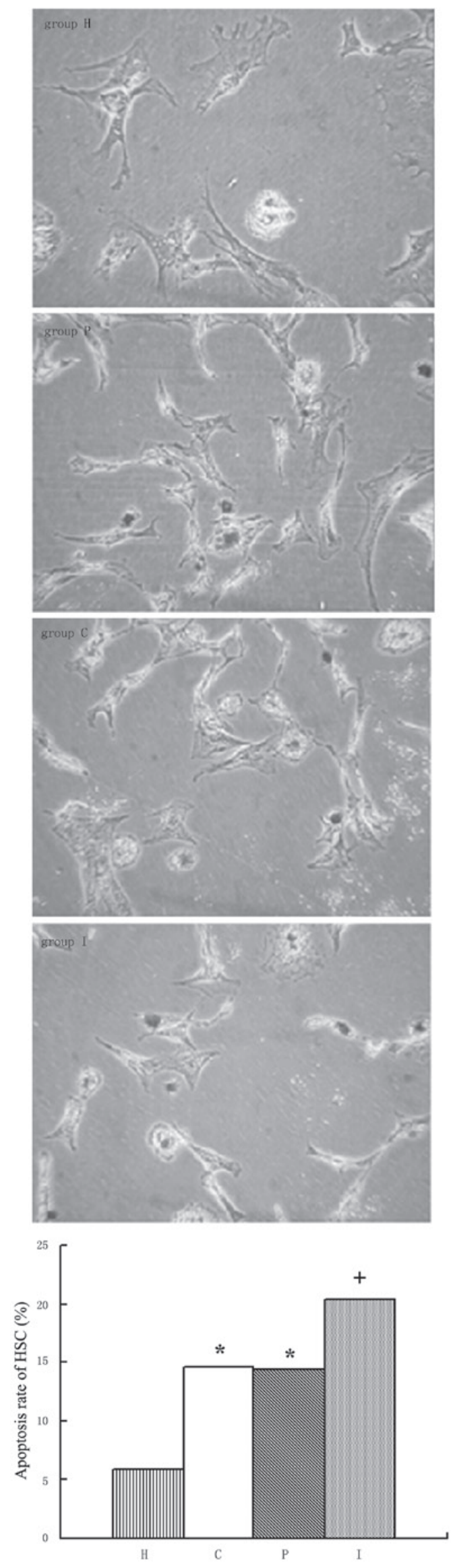

Figure 8. Apoptosis of hepatic stellate cells (HSCs) detected by terminal dUTP nick-end labeling (TUNEL). Group H, HSCs; groups C, P and I, HSCs co-cultured with BRL cells transfected with normal saline, pcDNA3.0 and pcDNA3.0-IL-10, respectively. ${ }^{*} \mathrm{P}<0.01$ vs. group $\mathrm{H}$; ${ }^{+} \mathrm{P}<0.01$ vs. group $\mathrm{P}$. 
inappropriate when treating a chronic disease such as liver fibrosis. Common liposomes have high safety but low transfection efficiency. The liposome JetPEI-Gal, a liposome linked to galactose which is able to specifically bind to the asialoglycoprotein receptors on liver cell membranes, should significantly increase the targeting and transfection efficiency for hepatocytes. In the present study, an eukaryotic expression vector for the rat IL-10 gene was successfully constructed and transfected into BRL cells. When delivered by the asialoglycoprotein receptor-mediated JetPEI-Gal liposomes, high expression levels of IL-10 were detected in BRL cells and their supernatant. It was confirmed that JetPEI-Gal liposomes had markedly higher transfection efficiency for hepatocytes than common liposomes. Furthermore, JetPEI-Gal liposomes are able to prolong the expression of IL-10 by hepatocytes. There was a divergence phenomenon between the mRNA and protein expression levels of IL-10 from 4 days post gene transfer. This supression of translation was possibly due to the super-high cell density at the late phase of cell culture. Whether these divergence phenomena appear in vivo requires further study.

BRL cells transfected with the pcDNA3.0 plasmid present a decelerating proliferation and an accelerating apoptosis. This may be due to the damage induced by a high quantity of plasmids entering the cells and the following heavy plasmid load. In the present study, we identified that the apoptosis of BRL cells induced by plasmid transfection was attenuated by IL-10 gene expression, which supports the efficacy of hepatocytetargeting IL-10 gene therapy.

It has been reported that heptocytes are able to accelerate the proliferation of HSCs $(20,21)$. Gressner et al found that when cultured in the serum-reduced supernatant of hepatocytes, HSCs appeared to undergo increased proliferation, but no diversion of phenotypes (22). In the present study, it was shown that hepatocytes not only accelerated the proliferation of HSCs but also promoted the activation of HSCs, which was characterized by enhanced contraction and increased expression of procollagen type I and $\alpha$-SMA. Saile et al reported that apoptosis was rare in quiescent HSCs, but markedly increased in activated HSCs, which suggests that apoptosis is an important mechanism in terminating the proliferation of activated HSCs (23). Our findings demonstrate that apoptosis becomes detectable in parallel with the HSC activation induced by BRL cells.

It has been verified that endogenous and exogenous IL-10 are able to inhibit liver fibrosis (3-6). In the present study, BRL cells transfected with the IL-10 gene displayed the ability to attenuate the proliferation of HSCs and their expression of procollagen type I and $\alpha$-SMA. As liver injury resolves, apoptosis of activated HSCs may be involved in the reversion of liver fibrosis (24). When HSCs were cocultured with IL-10 gene-modified BRL cells, a further acceleration of HSC apoptosis was identified in our study. This suggested that IL-10 plays its anti-fibrotic role not only by inhibiting the proliferation and activation of HSCs but also by enhancing the apoptosis of HSCs. These results are in agreement with findings from our previous studies using recombinant rat IL-10 $(25,26)$. They also demonstrate that IL-10 from hepatocytes with IL-10 gene amplification have an effect equivalent to that of exogenous IL-10 on HSCs.

\section{Acknowledgements}

This study was supported by Natural Science Foundation of Fujian Province, No. 2009J05065.

\section{References}

1. Friedman SL: Cytokines and fibrogenesis. Semin Liver Dis 19: 129-140, 1999,

2. Rockey DC: Current and future anti-fibrotic therapies for chronic liver disease. Clin Liver Dis 12: 939-962, 2008.

3. Thompson K, Maltby J, Fallowfield J, McAulay M, Millward-Sadler $\mathrm{H}$ and Sheron $\mathrm{N}$ : Interleukin-10 expression and function in experimental murine liver inflammation and fibrosis. Hepatology 28: 1597-1606, 1998,

4. Louis H, Van Laethem JL, Wu W, et al: Interleukin-10 controls neutrophilic infiltration, hepatocyte proliferation, and liver fibrosis induced by carbon tetrachloride in mice. Hepatology 28 : 1607-1615, 1998.

5. Nelson DR, Lauwers GY, Lau JY and Davis GL: Interleukin-10 treatment reduces fibrosis in patients with chronic hepatitis $\mathrm{C}$ : a pilot trail of interferon nonresponders. Gastroenterology 118: 655-660, 2000.

6. Wang XZ, Zhang LJ, Li D, Huang YH, Chen ZX and Li B: Effects of transmitters and interleukin-10 on rat hepatic fibrosis induced by $\mathrm{CCl}_{4}$. World J Gastroenterol 9: 539-543, 2003.

7. Rachmawati H, Reker-Smit C, Lub-de Hooge MN van Loenen-Weemaes A, Poelstra K and Beljaars L: Chemical modification of interleukin-10 with mannose 6-phosphate groups yields a liver-selective cytokine. Drug Metab Dispos 35: 814-821, 2007.

8. Hung KS, Lee TH, Chou WY, et al: Interleukin-10 gene therapy reverses thioacetamide-induced liver fibrosis in mice. Biochem Biophys Res Commun 336: 324-331, 2005.

9. Chen YX, Huang YH, Chen ZX, Zheng WD and Wang XZ: Construction of eukaryotic expression plasmid containing rat interleukin-10 gene and its expression in BRL cells in vitro. Xi Bao Yu Fen Zi Mian Yi Xue Za Zhi 24: 332-334, 2008 (In Chinese).

10. Ramm GA: Isolation and culture of rat hepatic stellate cells. J Gastroenterol Hepatol 13: 846-851, 1998.

11. Huhn RD, Radwanski E, O'Connell SM, et al: Pharmacokinetics and immunomodulatory properties of intravenously administered recombinant human interleukin-10 in healthy volunteers. Blood 87: 699-705, 1996.

12. Rachmawati H, Beljaars L, Reker-Smit C, et al: Pharmacokinetic and biodistribution profile of recombinant human interleukin-10 following intravenous administration in rats with extensive liver fibrosis. Pharm Res 21: 2072-2078, 2004.

13. Mathurin P, Xiong S, Kharbanda KK, et al: IL-10 receptor and coreceptor expression in quiescent and activated hepatic stellate cells. Am J Physiol Gastrointest Liver Physiol 282: G981-G990, 2002.

14. Safadi R, Ohta M, Alvarez CE, et al: Immune stimulation of hepatic fibrogenesis by CD8 cells and attenuation by transgenic interleukin-10 from hepatocytes. Gastroenterology 127: 997-1000, 2004.

15. Louis H, Le Moine O, Peny MO, et al: Production and role of interleukin-10 in concanavalin A-induced hepatitis in mice. Hepatology 25: 1382-1389, 1997.

16. Di Stefano G, Derenzini M, Kratz F, Lanza M and Fiume L: Liver-targeted doxorubicin: effects on rat regenerating hepatocytes. Liver Int 24: 246-252, 2004.

17. Wang S, Cheng L, Yu F, Pan W and Zhang J: Delivery of different length poly(L-lysine)-conjugated ODN to HepG2 cells using N-stearyl lactobionamide-modified liposomes and their enhanced cellular biological effects. Int J Pharm 311: 82-88, 2006.

18. Lan L, Chen Y, Sun C, Sun Q, Hu J and Li D: Transplantation of bone marrow-derived hepatocyte stem cells transduced with adenovirus-mediated IL-10 gene reverses liver fibrosis in rats. Transpl Int 21: 581-592, 2008.

19. Tashiro H, Shinozaki K, Yahata H, et al: Prolongation of liver allograft survival after interleukin-10 gene transduction 24-48 hours before donation. Transplantation 70: 336-339, 2000.

20. Gressner AM, Lotfi S, Gressner G and Lahme B: Identification and partial characterization of a hepatocyte-derived factor promoting proliferation of cultured fat-storing cells (parasinusoidal lipocytes). Hepatology 16: 1250-1266, 1992. 
21. Faouzi S, Lepreux S, Bedin C, et al: Activation of cultured rat hepatic stellate cells by tumoral hepatocytes. Lab Invest 79: 485-493, 1999

22. Gressner AM, Lotfi S, Gressner G, Haltner E and Kropf J: Synergism between hepatocytes and Kupffer cells in the activation of fat storing cells (perisinusoidal lipocytes). J Hepatol 19: 117-132, 1993.

23. Saile B, Knittel T, Matthes N, Schott P and Ramadori G: CD95/CD95L-mediated apoptosis of the hepatic stellate cell. A mechanism terminating uncontrolled hepatic stellate cell proliferation during hepatic tissue repair. Am J Pathol 151: 1265-1272, 1997.
24. Issa R, Williams E, Trim N, et al: Apoptosis of hepatic stellate cells: involvement in resolution of biliary fibrosis and regulation by soluble growth factors. Gut 48: 548-557, 2001

25. Zhang LJ, Zheng WD, Shi MN and Wang XZ: Effects of interleukin-10 on activation and apoptosis of hepatic stellate cells in fibrotic rat liver. World J Gastroenterol 12: 1918-1923, 2006.

26. Chen YX, Wang XZ, Weng SG, Chen ZX, Huang YH and Zhang LJ: Effects of interleukin-10 on the proliferation and Fas/Fas ligand expression of hepatic stellate cells. Zhonghua Gan Zang Bing Za Zhi 11: 637-640, 2003 (In Chinese). 